\title{
Hybrid Power System Frequency Control including Wind Farm using Battery Storage System
}

\author{
Anannya Mondal, Md. Rifat Hazari, Mohammad Abdul Mannan and Junji Tamura
}

\begin{abstract}
Fixed speed wind turbine-squirrel cage induction generator (FSWT-SCIG) based wind farm (WF) is increasing significantly. However, FSWT-SCIG have no frequency control capability, which creates a significant problem on power system steady-state stability. This paper represents a new operational strategy to control frequency of the entire power system including large-scale FSWT-SCIG based WF by using battery storage system (BSS). The proposed cascaded control of BSS is designed to provide effective amount of real power during steady-state period to damp frequency fluctuations. To evaluate the validity of the proposed system, simulation studies are executed on a reformed IEEE nine-bus power system with three synchronous generators (SGs) and SCIG-based WF along with BSS The simulation results indicate that the proposed system can be an effective solution to reduce frequency fluctuations of the hybrid power system during steadystate condition.
\end{abstract}

Keywords: FSWT-SCIG, Battery Storage System, Power System Stability, Synchronous Generator.

\section{Introduction}

Today's world facing global warming because of using extensive amount of fossil fuel based power stations to meet the electricity demand [1]. Meanwhile the beginning of the industrial revolution, the temperature of the earth has increased at a high rate, raising oceanic water levels in its wake. Not only the fossil fuels heat the earth, they produce unhealthy environments like air pollution, which adversely affects human health and body [1]. Due to the disadvantage of the conventional power plants, renewable energy has grown significantly since the last decade. Between different types of renewable energy sources, wind power (WP) is growing significantly since the last decade. Wind energy is such a clean energy, which

Anannya Mondal is completing M.Sc. in the department of EEE from American International University-Bangladesh (AIUB), Dhaka-1213, Bangladesh. Email: anannyamondal99@gmail.com Md. Rifat Hazari is an Assistant Professor of the Department of EEE, American International University-Bangladesh, 408/1, Kuratoli, Khilkhet, Dhaka-1229, Bangladesh. Email: rifat@aiub.edu Mohammad Abdul Mannan is a Professor and Director of the Department of EEE, American International University-Bangladesh, 408/1, Kuratoli, Khilkhet, Dhaka-1229, Bangladesh. Email mdmannan@aiub.edu

Junji Tamura is a Professor at EEE Dept. of Kitami Institute Technology, 165 Keon-cho, Kitami, Hokkaido, 090-8507, Japan. Email: tamuraj@mail.kitami-it.ac.jp can avoid 5.6 billion tons of $\mathrm{CO}_{2}$ by 2050, equivalent to the yearly emissions of the 80 most polluting cities in the world, home to around 720 million people [2]. This would help to save up to 4 million lives annually by 2030 by reduction pollution, because one in eight deaths in the world is linked to air pollution [3]. The new global total for wind power at the end of 2015 was $432.9 \mathrm{GW}$, which is a summative market growth of more than 17\% [4]. By 2030, wind power could reach $2110 \mathrm{GW}$ and supply up to $20 \%$ of worldwide [4].

This massive penetration of wind energy into the power system by replacing fossil fuel based power plants has introduced some burdens to the power grid.

Basically, FSWT-SCIG is mostly used to develop WF. SCIGs have some advantages, such as low cost, requires less maintenance, good speed regulation, high efficiency in converting mechanical energy to electrical energy, have better heat regulation, small and lightweight. However, it cannot ensure frequency stability of entire power system during steady-state period [5-6].

Therefore, a BSS system for SCIG-based WF is proposed in this paper to damp frequency oscillations. A suitable PI controller based cascaded control strategy is developed to ensure the frequency stability.

The steady-state response of the entire power system including IEEE nine-bus system, WF with BSS is compared with that of SCIG without BSS. Actual wind speed value of Hokkaido Island, Japan is considered for steady-state analysis. The simulation results clearly indicate that the frequency oscillations can be minimized successfully using proposed strategy.

\section{Model of Hybrid Power System}

The hybrid power system model presented in Fig. 1 is used for steady-state analysis. It has a WF and IEEE nine-bus main model. Basically three different conventional SGs are used for the main system. The ratings of the SGs: 150 MVA (SG1), 250 MVA (SG2) and 200 MVA (SG3).

AC4A type exciter model is used for all SGs as shown in Fig. 2 [7]. The thermal based power stations as depicted in Fig. 3 is considered for SG1 and SG2 on the other hand, hydro based power station is considered for SG3 as illustrated in Fig. 4 [7]. Here, the FSWTSCIG is linked to the main system at Bus 5 through $0.69 \mathrm{kV} / 66 \mathrm{kV}, 66 \mathrm{kV} / 230 \mathrm{kV}$ transformers and dual transmission line. 


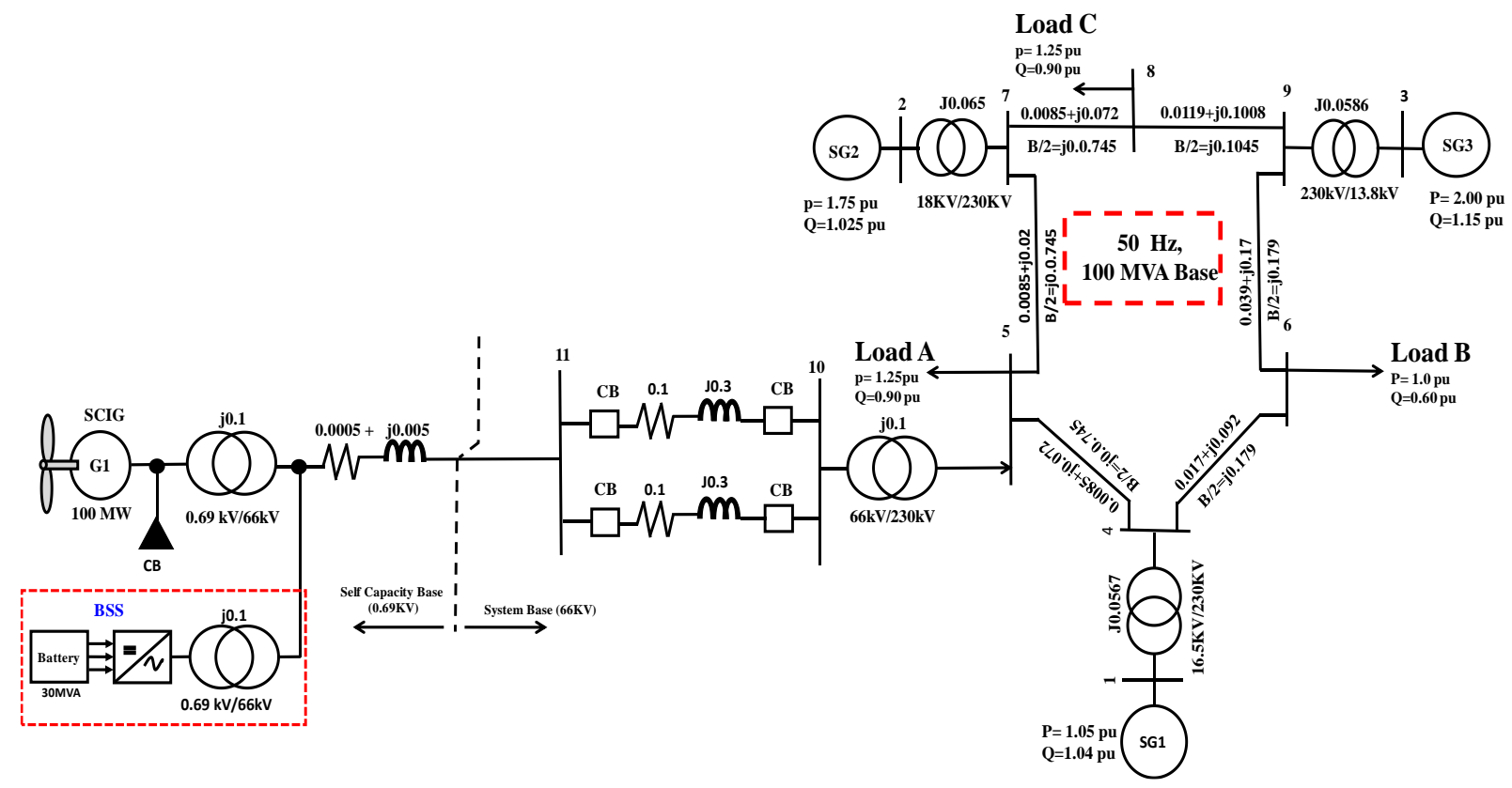

Fig. 1: Hybrid power system model.

The governor systems of SG1 and SG3 are

It has one SCIG (rated capacity: $100 \mathrm{MW}$ ) as shown in Fig. 1. The reactive power is delivered to the SCIG using capacitor bank during steady-state period. Additionally, BSS is connected next to the capacitor bank. The capacity of the BSS is 30 MVA. The frequency is $50 \mathrm{~Hz}$ and base power of the power system is $100 \mathrm{MVA}$.

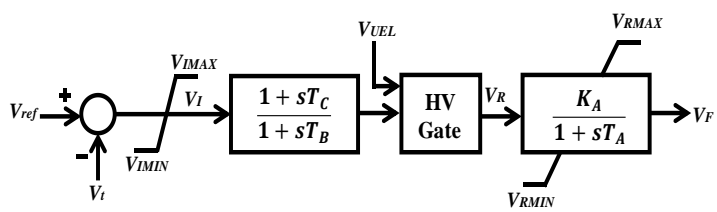

Fig. 2: Exciter model of SGs.

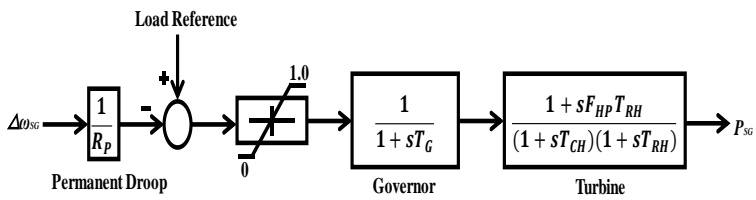

Fig. 3: Governor model of thermal turbine.

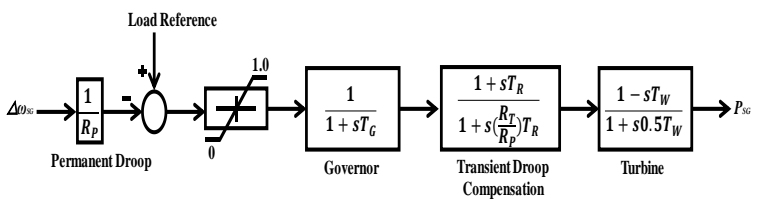

Fig. 4: Governor model of hydro turbine.

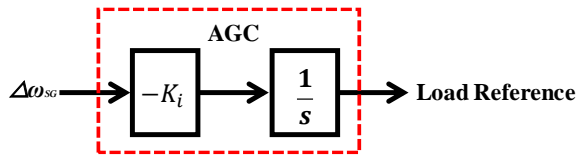

Fig. 5: AGC. controlled by an integral control to ensure automatic generation control (AGC) as depicted in Fig. 5.

\section{Model of Wind Turbine}

The expression of wind turbine mechanical power can be written as [8]:

$$
P_{w}=0.5 \rho \pi R^{2} V_{w}^{3} C_{p}(\lambda, \beta)
$$

Here, $P_{w}=$ captured wind power, $R$ =rotor blade radius, $\rho=$ air density, $C_{p}=$ power coefficient and $V_{w}$ $=$ wind speed.

The expression $C_{p}$ can be written as follows [9]:

$$
\begin{aligned}
& C_{p}(\lambda, \beta)=c_{1}\left(\frac{c_{2}}{\lambda_{i}}-c_{3} \beta-c_{4}\right) e^{\frac{-c_{5}}{\lambda_{i}}}+c_{6} \lambda \\
& \frac{1}{\lambda_{i}}=\frac{1}{\lambda-0.08 \beta}-\frac{0.035}{\beta^{3}+1} \\
& \lambda=\frac{\omega_{r} R}{V_{w}}
\end{aligned}
$$

Here, $\beta=$ pitch angle, $\omega_{r}=$ wind turbine rotor speed, $c_{1}$ to $c_{6}=$ wind turbine characteristic coefficients [9], and $\lambda=$ tip speed ratio.

Fig. 6 presents the characteristics curve of $C p$ vs $\lambda$. The curve is found for different $\beta$ from Equation (2). From the graph, the optimum $\lambda\left(\lambda_{\text {opt }}\right)=8.1$ and the optimum $C p\left(C p_{\text {opt }}\right)=0.48$.

Fig. 7 presents the model for blade pitch control system of FSWT [10]. In FSWT, it is used to control the power output of the SCIG for not exceeding the rated power. 


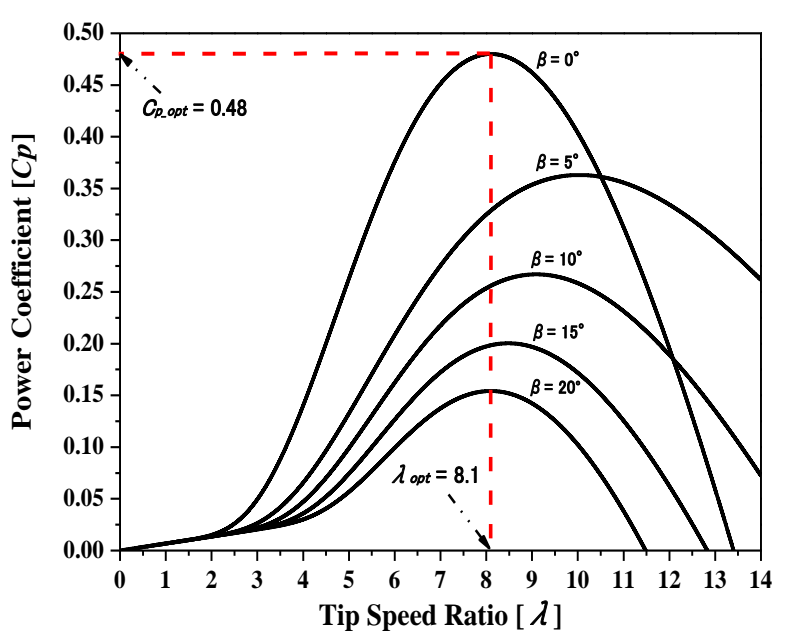

Fig. 6: $\mathrm{Cp}$ vs $\lambda$ characteristics curve.

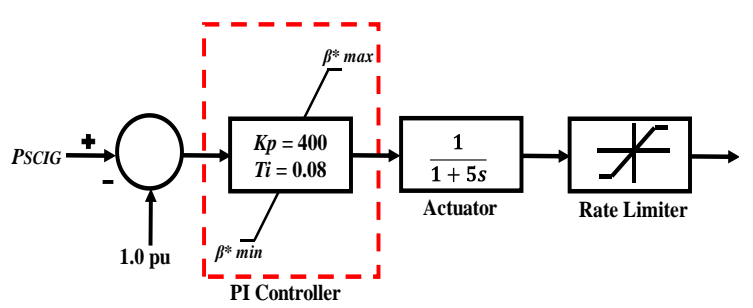

Fig. 7: Pitch controller of FSWT-SCIG.

\section{Proposed Coordinated Control of Battery Storage System}

The BSS model which is used in this study, is shown in Fig. 8. It consists of a lead-acid battery unit, voltage source converter (VSC) based on pulse width modulation (PWM) and step up transformer. For simplicity, the battery is represented by a constant DC voltage source. The DC voltage is transformed to grid synchronized three phase AC voltage using VSC.

The proposed control strategy of BSS is depicted in Fig. 9. The different error signals are compensated using four PI controllers based cascaded control techniques. The upper portion of the proposed control system controls the real power injected to the power grid system by adjusting the d-axis current $(I d)$ whereas lower portion is controlling the reactive power injected to the power system by adjusting the q-axis current $(I q)$. Additionally, in the upper portion the frequency of the grid system $\left(f_{\text {sys }}\right)$ is taken as feedback. Depending upon the frequency deviation, the upper controller portion will minimize the frequency fluctuations by injecting effective amount of real power from the BSS during steady-state condition. The trial and error techniques is applied to choose the droop gain $(K p)$ which ensures optimized result.

Finally, the reference voltages $\left(V a^{*}, V b^{*}\right.$ and $\left.V c^{*}\right)$ are compared with high frequency triangular carrier wave to get the gate drive pulses of VSC. In this way, the frequency fluctuations minimization can be ensured.

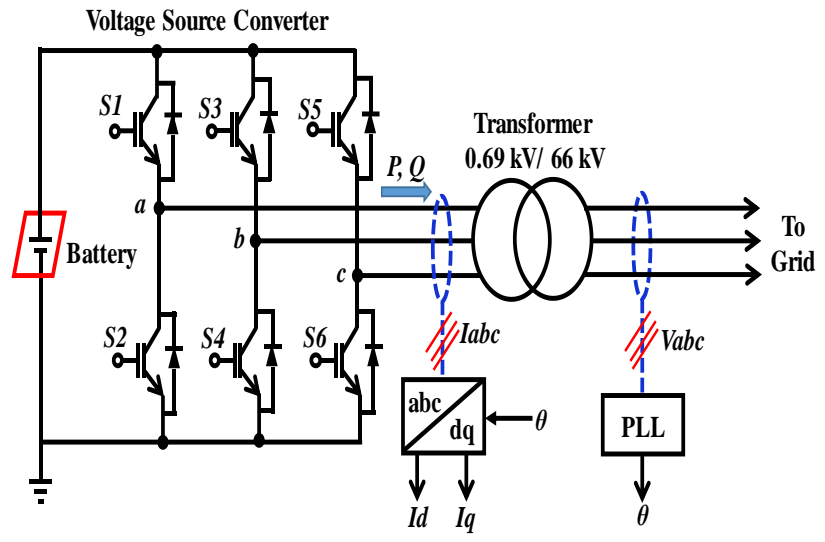

Fig. 8: Proposed BSS.

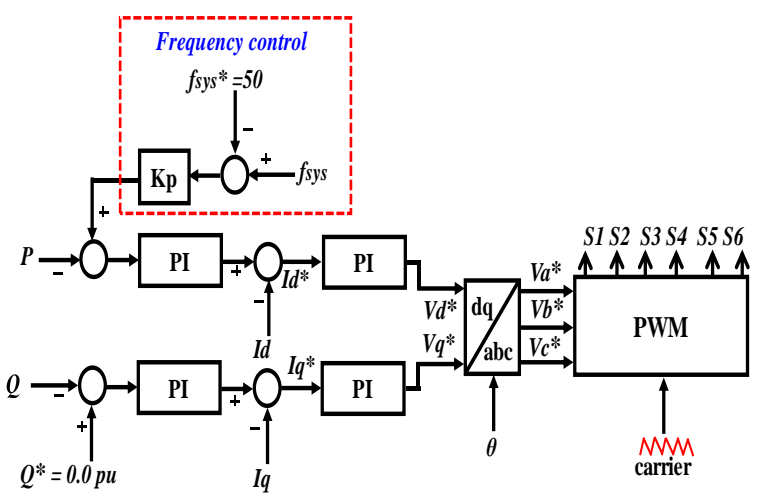

Fig. 9: Proposed Control Strategy of BSS.

\section{Simulation Results}

In this work, simulation investigation has been completed on the same hybrid power system model presented in Fig. 1. The well-known PSCAD/EMTDC software is used for simulation analysis. The system frequency is $50 \mathrm{~Hz}$. Two case studies are executed inorder to authenticate the appropriateness of the proposed BSS. In Case 1, simulation scrutiny is accomplished without BSS, and in Case 2, simulation scrutiny is accomplished by taking the proposed BSS.

The actual wind speed value of Hokkaido Island, Japan is taken in this steady-state analysis as depicted in Fig. 10. Fig. 11 shows the real power profile of SCIG-based WF. The responses are identical for both cases, because no control system is involved in SCIG. Additionally, the real power output is fluctuating because of the variable wind speed data. The BSS real power profile for Case 2 is illustrated in Fig. 12. From the figure, it is clear that BSS system can provide effective amount of real power based on the frequency fluctuations. Thus, the frequency fluctuation is smaller in Case 2 compared to Case 1 as depicted in Fig. 13, which validate the importance of the proposed BSS. Although, the frequency fluctuation is smaller in the proposed Case 2, but there is small variation. This is because the real wind speed data is used as mentioned earlier. Finally, Fig. 14 shows the real power profiles of conventional power plants (SGs). Finally, Fig. 15 presents the mechanical power output of FSWT. The 
response is identical for both cases, as no control system is involved in FSWT-SCIG.

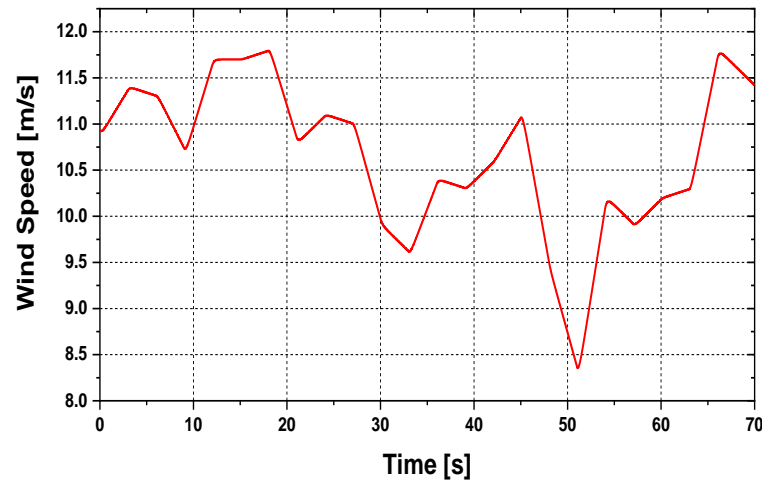

Fig. 10: Wind speed applied to FSWT-SCIG.

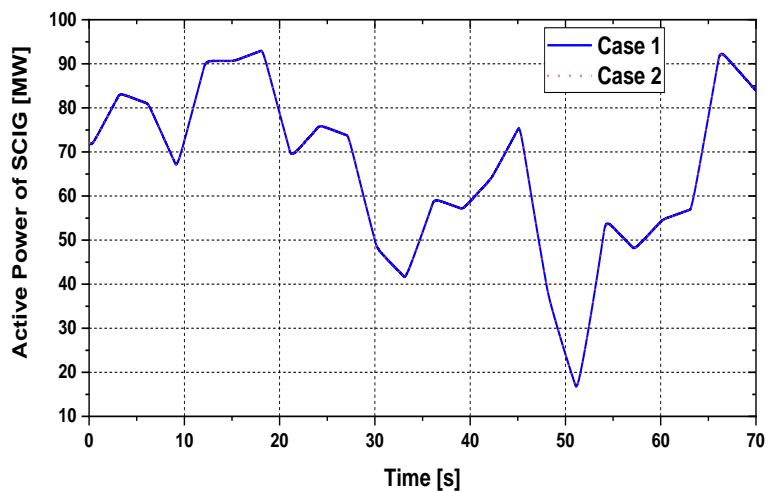

Fig. 11: Real power response of FSWT-SCIG.

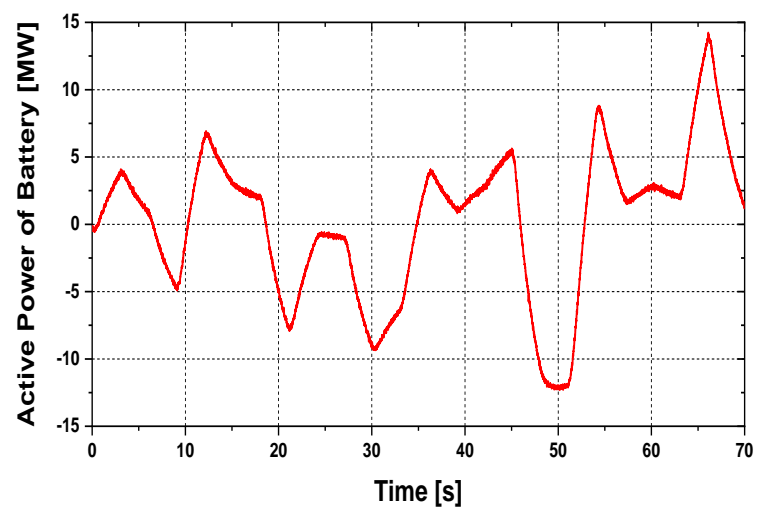

Fig. 12: Real power output of BSS (Case 2 only).

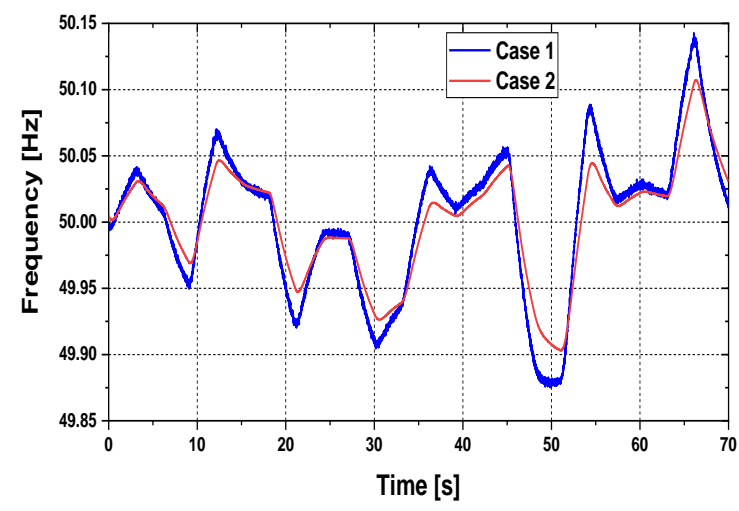

Fig. 13: Hybrid power system frequency response.

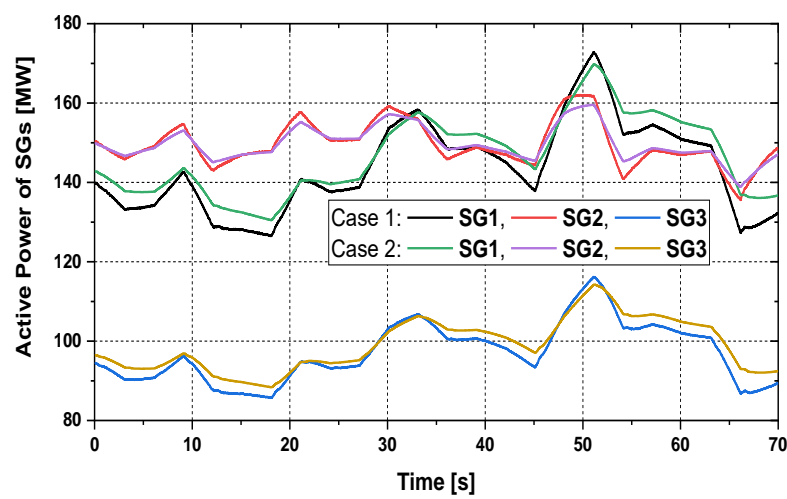

Fig. 14: Real power response of SGs.

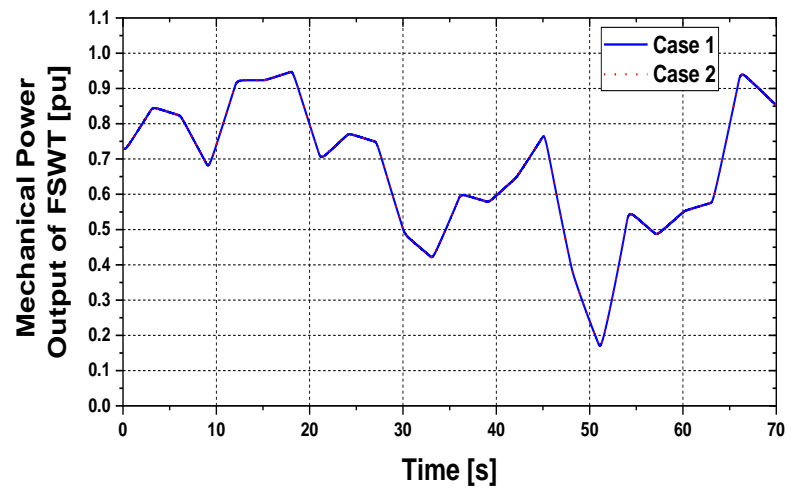

Fig. 15: Mechanical power output of FSWT.

Table 1 shows the $+\Delta \mathrm{f},-\Delta \mathrm{f}$ and $\sigma$ for both cases which is calculated from Fig. 13. The $+\Delta \mathrm{f},-\Delta \mathrm{f}$ and $\sigma$ are smaller in Case 2 compared to Case 1 .

Table 1: Different parameters comparison of frequency response graph.

\begin{tabular}{|c|c|c|}
\hline & Case 1 & Case 2 \\
\hline $\begin{array}{c}\text { Maximum frequency } \\
\text { deviation in positive } \\
\text { direction }(+\Delta \mathrm{f})\end{array}$ & 0.1428 & 0.1072 \\
\hline $\begin{array}{c}\text { Maximum frequency } \\
\text { deviation in negative } \\
\text { direction }(-\Delta \mathrm{f})\end{array}$ & -0.1249 & -0.0969 \\
\hline Standard deviation $(\sigma)$ & 0.0536 & 0.0419 \\
\hline
\end{tabular}

\section{Conclusion}

To minimize the frequency oscillations of a hybrid power system during steady-state period, a novel BSS based FSWT-SCIG is proposed in this paper. Wellknown PI based control strategy is used to control the BSS. Detail design procedure of hybrid power system model, FSWT-SCIG system and proposed BSS system along with control strategy are described adequately.

Different case studies are executed to show the usefulness of the proposed BSS using real wind speed data. The simulation results clearly indicate that based on proposed BSS real power, frequency oscillations can be minimized effectively by using the proposed BSS system. Therefore, this proposed control strategy has an encouraging potential value. 
As a future work, low voltage ride-through (LVRT) improvement during transient period using BSS system with FSWT-SCIG will be strong candidate.

\section{References}

[1] A. H. M. S. Ula, "Global warming and electric power generation: What is the connection?," in IEEE Transactions on Energy Conversion, vol. 6, no. 4, pp. 599-604, Dec. 1991 [2] Global status report 2017 [Online]. Available: https://www.worldgbc.org/sites/default/files/UNEP\%20188_ GABC_en\%20\%28web\%29.pdf [Accessed: 25 November 2019].

[3] Global Wind Energy Council (GWEC). Annual Market Update 2015, Global Wind Report. 2015.

Available online: http://www.gwec.net/ (accessed on 15 October 2017).

[4] Global Wind Energy Council (GWEC). Global Wind Energy Outlook 2016: Wind Power to Dominate Power Sector Growth. 2016. Available online: http://www.gwec.net/ (Accessed on 25 November 2019).

[5] M. R. Hazari, M. A. Mannan, A. Umemura, R. Takahashi and J. Tamura "Stabilization of Wind Farm by Using PMSG Based Wind Generator Taking Grid Codes into Consideration," Journal of Power and Energy Engineering, Vol. 6, No. 11, pp. 40-52, 2018.

[6] M. R. Hazari, M. A. Mannan, S. M. Muyeen, A. Umemura, R. Takahashi and J. Tamura "Fuzzy Logic based Virtual Inertia Control of DFIG based Wind Generator for Stability Improvement of Hybrid Power System," IEEJ Transactions on Power and Energy, Vol. 138, No. 8, pp. 733744, 2018

[7] P. Kundur, Power system stability \& control, McGrawHill Inc.

[8] M. Rosyadi, A. Umemura, R. Takahashi, J. Tamura, N. Uchiyama and K. Ide, "Simplified model of variable speed wind turbine generator for dynamic simulation analysis," IEEJ Transactions on Power and Energy, Vol. 135, No. 9, pp. 538-549, 2015

[9] S. M. Muyeen, J. Tamura and T. Murata, Stability augmentation of a grid connected wind farm, London, Springer-Verlag, 2009

[10] J. Liu; M. Rosyadi, A. Umemura, R. Takahashi, J. Tamura, "Control Method of Permanent Magnet Wind Generators in Grid Connected Wind Farm to Damp Load Frequency Oscillation," IEEJ Transactions on Power and Energy Vol. 134, No. 5 pp. 393-398, 2014, 134, pp. 393-398.

Anannya Mondal received her B.Sc. Engg. Degree in

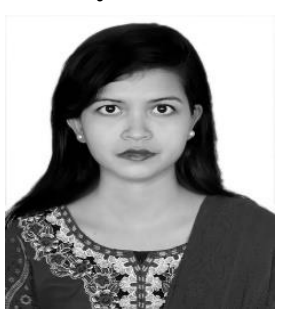
Electrical and Electronic Engineering from American International University-Bangladesh (AIUB) in december 2016. Currently she is completing her M.Sc. Engg. Degree in Electrical and Electronic Engineering from American International University-Bangladesh (AIUB) and working as an Adjunct Lecturer in the Electrical and Electronic Engineering department at Sonargoan University. Her research interests are renewable energy systems, power system Analysis in transient condition.
Md. Rifat Hazari received his B.Sc. Engg. and M.Sc. Engg.

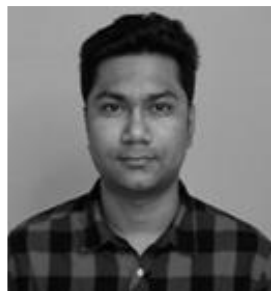

Degrees in Electrical and Electronic Engineering from American International University-Bangladesh (AIUB) in August 2013 and December 2014, respectively and Ph.D. Degree in Energy Engineering from Kitami Institute of Technology (KIT), Japan, in March 2019. He served as a Lecturer in Electrical and Electronic Engineering department at AIUB. Currently, he is working as an Assistant Professor in the Electrical and Electronic Engineering department at AIUB. He received the MINT (Academic Excellence) Award 2017 from KIT for the outstanding research of 2017 academic year, Best Paper Award in the Australasian Universities Power Engineering Conference 2017, Melbourne, Victoria, Australia and Best Presentation Award in the IEEJ Branch Convention 2017, Hakodate, Japan. His research interests are renewable energy systems (especially wind power \& photovoltaic power systems), power system stability and control, microgrid and hybrid power systems, HVDC system, analysis and control of rotating electrical machines.

Mohammadad Abdul Mannan was born in Laxmipur,

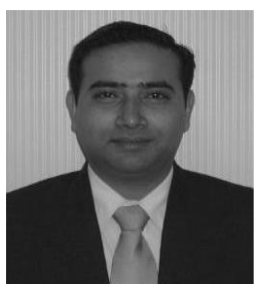
Bangladesh on January 01,1975 . He received his B. Sc. Eng. Degree from Rajshahi University of Engineering and Technology (RUET former BITR), Bangladesh, in 1998, and Masters of Eng. and Dr. of Eng. degrees from Kitami Institute of Technology, Japan, in 2003 and 2006 respectively, all in electrical engineering. He then joined in the American International University Bangladesh (AIUB) as an Assistant professor in May 2006. He served in AIUB as an Associate Professor from December 2013 to November 2016. Now he is working as a Professor and Director of Faculty of Engineering in AIUB. His research interests include electric motor drive, power electronics, power system, wind generation system and control of electric motor, power electronic converters, power system, and wind generation system. Prof. Dr. Mannan is a member of the IEB and IEEE.

Junji Tamura received his B. Sc. Eng. Degree from Muroran

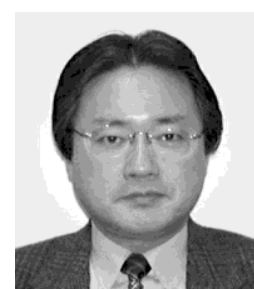
Institute of Technology, Japan, in 1979, and M.Sc. Eng. and Dr. Eng. degrees from Hokkaido University, Japan, in 1981 and 1984 respectively, all in electrical engineering. $\mathrm{He}$ became a lecturer in 1984, an Associate Professor in 1986, and a Professor in 1996 at the Kitami Institute of Technology, Japan. Prof. Dr. Tamura is a Senior Member of the IEEE Power Engineering Society. 